\title{
Nekrolog.
}

\section{Dr. Raffaele Zoja $†$.}

Am 26. September dieses Jahres verunglïckte durch Absturz zugleich mit einem jüngeren Bruder der jugendliche Forscher Dr. RAFf. ZoJa. Der Verstorbene war am 10. März 1869 zo Pavia als Sobn des dortigen angesehenen Anatomen and Physiologen geboren nnd bekleidete seit dem Jahre 1890 die Stelle eines Assistenten am physiologischen und vergleichend-anatomischen Institute daselbst. Mehrfachen lïngeren Urlanb verwandte er zu seiner weiteren vielseitigen Ausbildung in verschiedenen Instituten seiner Heimat und des Auslandes.

Trotzdem ihn der Tod so früh ereilte, verdankt ihm die Wissenschaft bereits eine beträchtliche Anzahl werthvoller wissenschaftlicher Arbeiten meist beschreibend zoologischen sowie physiologischen, zuletzt auch entwickelnngsmechanischen Inhalts. In Anerkennung dieser Leistungen wurde er in diesem Jahre zum korrespondirenden Mitgliede des Istituto Lombardo di Scienze e Lettere ernannt und durch die Verleihung der goldenen Medaille der Società italiana dei XL ausgezeichnet.

Seine an sehr werthvollen entwickelungsmechanischen Ergebnissen reiche Untersuchung: Sullo sviluppo dei blastomeri isolati dalle uova di alcune meduse (e di altri organismi) ist in dem Laboratoritum des Prof. Nicoladus Kleinenberg in Messina angestellt; sie ist eine Zierde dieses Arçhivs (s. Bd. I und II). Die Entwickelungsmechanik verliert in ihm einen begeisterten und zu großen Hoffnungen berechtigenden Anhänger. 